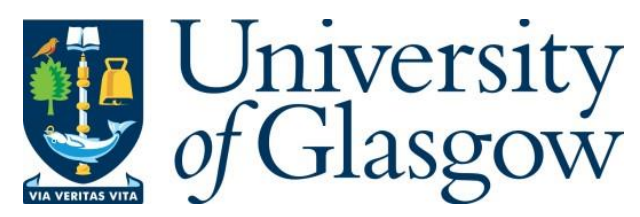

Christelis, D., Georgarakos, D., Jappelli, T. and van Rooij, M. (2020) Trust in the central bank and inflation expectations. International Journal of Central Banking, 16(6), pp. 137.

There may be differences between this version and the published version. You are advised to consult the publisher's version if you wish to cite from it.

http://eprints.gla.ac.uk/196565/

Deposited on: 18 September 2019

Enlighten - Research publications by members of the University of Glasgow http://eprints.gla.ac.uk 


\title{
Trust in the Central Bank and Inflation Expectations \#
}

\author{
Dimitris Christelis \\ University of Naples Federico II, CSEF, CFS, and Netspar \\ Dimitris Georgarakos \\ European Central Bank \\ Tullio Jappelli \\ University of Naples Federico II, CSEF and CEPR \\ Maarten van Rooij \\ De Nederlandsche Bank and Netspar
}

July 2, 2019

\begin{abstract}
Using micro data from the 2015 Dutch CentERpanel, we examine whether trust in the European Central Bank (ECB) influences individuals' expectations and uncertainty about future inflation, and whether it anchors inflation expectations. We find that higher trust in the ECB lowers inflation expectations on average, and significantly reduces uncertainty about future inflation. Moreover, results from quantile regressions suggest that trusting the ECB increases (lowers) inflation expectations when the latter are below (above) the ECB's inflation target. These findings hold after controlling for people's knowledge about the objectives of the ECB.
\end{abstract}

JEL Classifications: D12, D81, E03, E40, E58

Keywords: Inflation expectations, inflation uncertainty, anchoring, trust in the ECB, subjective expectations

\footnotetext{
\# We are grateful to Pierpaolo Benigno (Editor) and two anonymous referees for their constructive comments. We also thank seminar participants at the ECB conference on 'Understanding inflation: lessons from the past, lessons for the future?', the ECB Household Finance and Consumption Network, Deutsche Bundesbank, De Nederlandsche Bank, Bank of Greece and the University of Nottingham for helpful comments. Tullio Jappelli and Dimitris Christelis acknowledge financial support from the Italian Ministry of Universities and Research. The opinions expressed in the paper are those of the authors and do not reflect the views of the European Central Bank and De Nederlandsche Bank.
} 


\section{Introduction}

For central banks, the management of economic expectations has become a key tool in conducting monetary policy (Blinder et al., 2008). To effectively manage expectations, a high level of public trust in central banks is necessary. For instance, a high level of trust in the commitment and ability of the European Central Bank (ECB) to keep inflation below, but close to, 2 percent can anchor medium- and long-term inflation expectations on this target, and make the public view deviations from the target as temporary ones. More generally, a trustworthy central bank is more likely to increase public confidence about future price stability and the prospects of the economy, thereby boosting economic growth. ${ }^{1}$

A number of recent studies document that inflation expectations feed into important household financial decisions. Malmendier and Nagel (2016) show that households expecting higher inflation are less likely to invest in long-term bonds and more likely to borrow through fixed-rate mortgages compared to low inflation expectations households. Armantier et al. (2015) conduct a financially incentivized investment experiment and find that individuals' reported inflation expectations influence their investment choices in a way that is consistent with economic theory. Moreover, D'Acunto et al. (2016) show that an increase in inflation expectations implies a higher readiness to purchase durable goods.

To the best of our knowledge, existing literature does not provide empirical evidence on the relationship between trust in central banks and inflation expectations. ${ }^{2}$ Our paper fills this gap by

\footnotetext{
${ }^{1}$ For instance, persistently high inflation has been historically linked to increased uncertainty about price evolution and low public confidence in the economy's prospects. Such an environment has typically adverse effects on individuals' saving, consumption and investment decisions. As Bernanke (2013) states: "Expectations matter so much that a central bank may be able to help make policy more effective by working to shape those expectations."

${ }^{2}$ The relation between trust and inflation expectations has been recently recognized as a highly policy relevant topic that merits empirical investigation: "Another field in which public trust in central banks might prove important is for the understanding of the formation of household inflation expectations [....] If low public trust in central banks is
} 
investigating whether citizens' trust in the ECB contributes to individuals' expectations and uncertainty about price growth and the extent to which these expectations are anchored at the ECB's medium term inflation target of below, but close to, 2 percent. More broadly, our paper contributes to existing literature which finds that higher social capital and trust are conducive to better economic outcomes such as higher growth (see, e.g., Zak and Knack, 2001; Tabellini, 2010).

We use recent micro data from the CentER panel, a representative survey of the Dutchspeaking population in the Netherlands, sponsored by the Dutch National Bank (DNB). We survey individuals during the first half of 2015 and ask them a set of specially designed questions that allow us to construct individual-specific measures of expected inflation and inflation uncertainty. Given that the ECB's policy impacts a broad range of economic outcomes, we collect similar information on expectations regarding economic growth. We ask also how much individuals trust the ECB. Similar trust questions that aim to measure public trust in the ECB and in other European institutions are regularly asked in Eurobarometer surveys since the early 2000s. Existing literature has used Eurobarometer data to examine possible determinants of the ECB trust (Bursian and Fürth, 2015; Ehrmann et al., 2013). Instead, our paper explores the influence of trust in the ECB on inflation expectations. Finally, the survey contains a series of questions about the objectives of the ECB that allow us to distinguish whether reported trust in the ECB reflects the perceived credibility of the institution or simply knowledge about its role.

Our analysis offers a number of novel findings. First, higher trust in the ECB induces, on average, lower one year ahead inflation expectations. This relationship, however, is not uniform

associated with higher household inflation expectations, then swings in public trust in ECB also directly affect its ability to deliver on its mandate, although the empirical relevance of this proposition has yet to be tested" (Ehrmann et al., 2013, pp. 782-783). 
across different percentiles of the distribution of inflation expectations. Second, higher trust contributes significantly to lower individual uncertainty about future price growth, thus implying a form of anchoring of inflation expectations. Third, higher trust in the ECB is associated with higher inflation expectations when the latter are at the lower end of the sample distribution, while the opposite is true when people have inflation expectations at the upper end. This effect is particularly strong for those who report inflation expectations above the ECB target, while it is less robust for the part of the distribution that corresponds to expected inflation that is below, but close to, 2 percent.

Taken together, these results point to the role that trust in the ECB can play in anchoring consumers' inflation expectations around the ECB's medium-term inflation target. If expectations are well-anchored around the target, the public should be confident about its inflation estimate and react little to short movements of higher or lower than expected inflation. Moreover, if anchoring of public expectations occurs close to the central bank's inflation target, equilibrium prices should adjust faster towards this target (Bernanke, 2013).

As the survey was conducted in the first half of 2015 , it is noteworthy that the estimated effect of trust on anchoring inflation expectations is economically important even in an environment of low interest rates and inflation. This suggests that factors such as citizens' trust in the central bank can be important when conventional monetary policy tools turn out to be least effective.

Fourth, we examine whether estimated effects of trust in the ECB reflect public knowledge about the ECB objectives per se (e.g. the numerical target for inflation) or credibility more broadly defined (e.g. in ECB's commitment to maintain price stability). To this end, we control for respondents' knowledge regarding the ECB's objectives or their financial sophistication and results remain unchanged. This suggests that people's perceptions about the credibility of an institution 
can influence their inflation expectations over and above their knowledge about the specific objectives of the institution. It also highlights the long-term advantages of establishing a reputation for central bank credibility as it could operate beyond precise knowledge about central bank's objectives or temporary deviations from them. ${ }^{3}$ Fifth, trust in the ECB is also positively associated with expectations about economic growth, but not with the expected variability of output growth.

In the investigation, we estimate several empirical models to make sure that the effects we uncover are due to individuals' trust in the ECB as an institution and not to other possible confounding factors. As we discuss in detail in Section 4, we identify our parameters of interest through instrumental variable (IV) estimation using information on episodes of cheating by repair persons that respondents have experienced in the past few years. We assume that exposure to such events is correlated with the social capital component of trust in the ECB, but has not an independent effect on inflation expectations. We also use, as a second instrument, the trust that respondents have in other people, as interpersonal trust is unlikely to directly shape inflation expectations. The test of the overidentification restrictions strongly suggests that the null hypothesis of the exogeneity of these instruments cannot be rejected.

Moreover, we control not only for standard socio-economic characteristics but also for respondents' general economic knowledge by means of three standard questions that have been developed by Lusardi and Mitchell (2014) and are widely used to measure financial literacy. In a related vein, we measure and control for individuals' specialized knowledge about the ECB's objectives. The main findings on the role of trust in the ECB remain unaffected when we control for these indicators of knowledge about the ECB and financial literacy, which suggests that genuine

\footnotetext{
${ }^{3}$ Kril et al. (2016) provide a thorough discussion of the economic advantages of central bank credibility.
} 
trust in the institution impacts inflation expectations over and above knowledge about the ECB's mission or economics in general. Furthermore, our main findings are unaffected when a measure of individual optimism is included in our specifications.

The remainder of the paper is organized as follows. Section 2 reviews relevant studies on inflation expectations and trust in institutions. Section 3 describes the survey data. Section 4 presents the baseline empirical results on inflation expectations, uncertainty and anchoring. Section 5 presents a number of robustness checks, and Section 6 contains additional results on expectations about economic growth and output variability. Section 7 summarizes our main findings.

\section{Inflation expectations and trust}

Our paper spans different strands of the literature on inflation expectations and trust. Recent studies explore links between survey-based inflation expectations, anchoring around central bank's inflation target and understanding of monetary policy operations. In particular, Kumar et al. (2015) survey firms' managers in New Zealand and find evidence that their inflation expectations are not anchored, despite the Reserve Bank's inflation targeting for more than twenty-five years. Carvalho and Nechio (2014) provide evidence that some US households form expectations consistent with a Taylor rule. Kril et al. (2016) use survey data from Israel to examine the determinants of central bank credibility and trust. Based on a detailed set of questions, they document that the public perception about central bank credibility is primarily linked to views regarding the professionalism and independence of the central bank and not with its transparency per se.

While there are only few studies using survey-based information on inflation expectations, there are several papers on anchoring and inflation expectations based upon financial market instruments such as inflation options, swaps and index linked securities. Some of these studies 
investigate central bank credibility, mostly after estimating it using financial market-based expectations (see, e.g., Gerlach-Kristen and Moessner, 2014; Gürkaynak et al., 2010). Kril et al. (2016), on the other hand, argue that these inflation expectations reflect the combined assessment of economic conditions and central bank credibility. Instead, they measure central bank credibility based upon the confidence of the public in central bank forecasts for inflation and economic growth. Their discussion and results indicate that while trust and credibility are multidimensional concepts, they are closely related to each other. ${ }^{4}$ In our paper, we interpret trust as a measure of the institutional credibility of the ECB, while in a robustness analysis we show that such institutional trust is not confounded by knowledge of the ECB's objectives. ${ }^{5}$

A related group of studies focuses on the role of central bank communication for financial market outcomes; Blinder et al. (2008) provide a thorough review. For example, Ehrmann and Fratzscher (2005) show that press statements by central banks have an immediate impact on financial markets and also affect the latter's ability to anticipate future monetary policy decisions. In contrast to these studies, we elicit survey-based consumer expectations on future inflation and its uncertainty and link them to reported trust in the ECB.

There is also a large body of literature studying the implications of trust in other people and social capital in different domains: economic growth (Zak and Knack, 2001; Guiso et al., 2004; Tabellini, 2010), confidence in the government (Knack and Keefer, 1997), financial integration (Ekinci et al., 2009), cross-country trade (Guiso et al., 2008), and household portfolios (Guiso et

\footnotetext{
${ }^{4}$ Indeed, the concept of central bank credibility was popularized as a solution to the time-inconsistency problem discussed by Kydland and Prescott (1977). One solution to this problem was to delegate monetary policy to a central bank or another institute with a high perceived credibility so that the public can have sufficient trust in the central banks' ability to withstand the temptation to create surprise short-term inflation.

${ }^{5}$ In the terminology of Kril et al. (2016), the knowledge component refers to reasoned trust/credibility while institutional trust refers to an affective form of trust/credibility.
} 
al., 2008; Georgarakos and Pasini, 2011). Another group of studies explores the determinants of trust in institutions, and central banks in particular. ${ }^{6}$ A robust finding of the literature on social capital is that trust in other people changes slowly over time, given that social capital consists of a large inherited component of social values and norms (Tabellini, 2010). ${ }^{7}$ On the other hand, Stevenson and Wolfers (2011) point out that specific trust in financial institutions is more responsive to prevailing economic conditions.

\section{The CentER Internet panel}

We use data from the CentER Internet panel, which is sponsored by DNB and maintained by CentERdata at Tilburg University. ${ }^{8}$ The baseline survey is conducted annually, and collects detailed information on a range of demographic and economic variables for a representative sample of Dutch-speaking households. In addition to the baseline survey, respondents answer questions during the course of a year in special purpose surveys.

We designed such a special purpose survey that measures individuals' expectations and uncertainty about future price growth as well as trust in the ECB. We administered the special survey to every panel participant aged 18 and older in January 2015. The survey was repeated in June 2015 to account for a possible seasonal pattern in responses and to increase sample size.

To elicit the distribution of expected inflation we follow a similar procedure as in Guiso et al. (2002; 2013) and Christelis et al. (2019), who estimate the subjective distribution of expected

\footnotetext{
${ }^{6}$ For recent studies see Bursian and Fürth (2015), Wälti (2012), Ehrmann et al. (2013) or Van der Cruijsen et al. (2016). ${ }^{7}$ Societal attitudes are often considered as slow-moving, but there are also instances that they adapt relatively fast to the environment. For example, Guiso et al. (2006) refer to culture as those customary beliefs and values that are transmitted fairly unchanged from generation to generation. On the other hand, Fernandez (2011) mentions as a counterexample the rapid change (i.e., within half a century) in attitudes towards married women working.

${ }^{8}$ Panel members are recruited via personal or telephone interviews. If, after being selected for panel participation, it turns out that respondents have no computer with Internet access, CentERdata provides them the necessary equipment.
} 
income, pension replacement rate and consumption, respectively. Specifically, we ask respondents to report the minimum $\left(y_{m}\right)$ and the maximum $\left(y_{M}\right)$ values of percentage change in the level of prices twelve months ahead. Subsequently, we ask them to indicate on a 0-100 scale the probability that the average change in prices in the next twelve months will be higher than the mid-point between the reported minimum and maximum, i.e., $\pi=\operatorname{Prob}\left(y>\left(y_{m}+y_{M}\right) / 2\right)$. The questions we use are reported in Online Appendix A.1.

To estimate the moments of the subjective distribution of expected inflation we rely on the assumptions and methods used by Guiso et al. (2002) and Christelis et al. (2019) to estimate the subjective distribution of future income and consumption, respectively. We assume that the subjective distribution is either simple triangular (i.e., symmetric around $\left(y_{m}+y_{M}\right) / 2$, assuming $\pi=0.5)$, or split triangular $(\pi \neq 0.5$; see Figure A.1. in Online Appendix A.1). Based on the elicited values of $y_{m}, y_{M}$ (and of $\pi$ if we assume a split triangular distribution) we compute the individual-specific mean and standard deviation of the distribution of expected inflation one year ahead. The formulae of these statistics are reported in Online Appendix A.2. ${ }^{9}$

We set values of the moments of the individual-specific subjective expected inflation distributions to missing when $y_{m}, y_{M}$ or $\pi$ are missing, or when respondents choose the 'don't know' option. The original sample includes 4,333 observations in the two survey waves. Due to missing values, the estimation sample includes 3,117 observations that allow the computation of inflation expectations using the simple triangular distribution, and 3,019 observations using the split triangular distribution.

\footnotetext{
${ }^{9} \mathrm{We}$ assume that $y_{m}$ and $y_{M}$ represent the actual minimum and maximum of the distribution. This is potentially a strong assumption. Dominitz and Manski (1997) use the percentage chance format to elicit the subjective income distribution, and show that individuals associate the "lowest possible" (and "highest possible") with low (respectively high) probability.
} 
The survey also asks individuals to indicate their level of trust in the ECB on a 0 to 10 scale, where 0 denotes no trust in the ECB whatsoever, while 10 denotes full trust. A similar question has been regularly asked in Eurobarometer surveys since the early 2000s so as to measure public trust in the ECB as well as in other institutions such as the United Nations, the European Union, the national Parliament and the national government. ${ }^{10}$ Eurobarometer data have been used by several studies to examine determinants of trust in the ECB or its evolution over time (see, e.g., Bursian and Fürth, 2015; Ehrmann et al., 2013; Wälti, 2012).

It is important to note that we ask the question on trust in the ECB without making any explicit reference to its objective of an inflation rate at or slightly below 2 percent. We do this for a number of reasons. First, we want to avoid conditioning the answers to the question on trust in the ECB. Given respondents' expected inflation, reminding them of the ECB's target inflation rate may change their answer. For instance, those who expect inflation next year to be 3 percent, when reminded that the ECB target rate is 2 percent, could reduce their reported trust. Second, we need to measure respondents' trust in the ECB given their current knowledge about economic affairs, without influencing this knowledge. Third, we aim to distinguish the notion of trust as institutional credibility from that of trust as institutional knowledge. This is why we control separately for the latter in our empirical specification, as discussed in Section 5 below. Making this distinction would have been impossible if we had mentioned explicitly the ECB inflation target in the question. Finally, while the primary target of the ECB is the inflation rate, its mandate states that it also aims

\footnotetext{
${ }^{10}$ The Eurobarometer question has three answer options: "Tend to trust", "Tend not to trust", or "Do not know". Our question asks for the intensity of trust using a $0-10$ scale (similar to the answer scale in questions on trust in other people used in surveys such as the European Social Survey).
} 
to promote economic growth, with no prejudice to achieving its inflation target. The weight given to the two objectives can vary over time in practice.

To separate the notions of trust and institutional knowledge, we ask a series of questions to measure knowledge about the ECB's objectives and basic financial literacy (see Online Appendix A.1 for the exact wording of these questions). Other studies have asked related questions that capture knowledge of the ECB's objectives. For instance, Van der Cruijsen et al. (2015) find a low prevalence of knowledge of the ECB's objectives. In our survey, we present six statements about the ECB's objectives. These statements mention specific numerical targets (e.g., for unemployment), in order to make sure that individuals are not confused with the fact that the ECB's policies can have broader positive economic consequences beyond price stability. Importantly, to avoid framing effects, we place the questions on expected inflation, trust in the ECB and knowledge about its objectives in separate sections of the questionnaire. ${ }^{11}$

To purge the relation between trust and inflation expectations from the effect of financial literacy, we ask the three basic financial literacy questions proposed by Lusardi and Mitchell (2014). The questions aim to capture individuals' numeracy and understanding of basic economic concepts such as interest rates, inflation and risk diversification, and have been used in many studies and countries (see Lusardi and Mitchell, 2014, for an overview).

Figures 1 and 2 show the distribution of the expected minimum and maximum levels of inflation 12 months ahead. ${ }^{12}$ For each observation in the sample, the maximum is greater than the

\footnotetext{
${ }^{11}$ As the latter set of questions makes reference to numerical targets that may (or may not) be among the objectives of the ECB, we have placed them in the last part of the questionnaire to avoid bias in the answers to questions on inflation expectations and/ or trust in the ECB.

12 Note that while our survey focuses on 12 months ahead inflation expectations, in recent consumer expectations surveys, respondents seem to provide similar answers to questions about short term (1 year) and medium term ( 3 year) inflation expectations (see, e.g., the New York Federal Reserve Bank's online reports of their survey on consumer expectations: https://www.newyorkfed.org/microeconomics/sce\#tindicators/inflation-expectations/g1).
} 
minimum. Figure 3 illustrates the distribution of the probability that the expected inflation is above the mid-point of the expected minimum and maximum values. As can be seen, there is a prevalence of "50 percent" responses but also a sizable number of responses with values larger or smaller than 50 percent. We note that responses to the question on this probability, which is arguably more difficult to answer, are not used in our baseline regressions, which rely on expectations computed using the simple triangular distribution.

Table 1 reports cross-sectional estimates of the median and coefficient of variation of the subjective distributions of expected inflation and expected growth, assuming that the underlying distribution is a simple (i.e., symmetric) triangular. At the median, the minimum expected inflation is 1 percent, while the maximum is 2 percent (the means are equal to 1.3 percent and 2.7 percent, respectively). The median probability is 0.50 (average 0.47 ). Assuming that the distribution is simple triangular, we estimate that the sample median of expected inflation is 1.6 percent (average 2 percent), while the median (mean) variance of the distribution of expected inflation is 0.04 percent $(0.21$ percent $)$. The coefficient of variation of the distribution of expected inflation, that is, the ratio of its standard deviation to its mean, is 1.09 , which implies that respondents experience considerable uncertainty about future inflation.

Given that inflation in the Netherlands in 2015 and 2016 was extremely low by historical standards ( 0.2 and 0.1 percent according to the Harmonized Index of Consumer Prices), the median expected inflation (1.6 percent) turned out to be an overestimate of the realized values. This is in line with evidence from other surveys on inflation expectations (see Kliesen, 2015, and Coibion and Gorodnichenko, 2015, for evidence from the University of Michigan Survey of Consumers), and could also reflect perceptions of price developments in the particular bundle of goods that each household regularly spends on. 
The respective sample median (mean) of expected GDP growth is 1.5 (1.47) percent, while the median (mean) variance of the distribution of expected growth is 0.02 percent $(0.11$ percent). As regards trust in the ECB (asked on a 0 to 10 scale), the median (mean) is 5 (4.77) and the standard deviation is 2.16. The table also shows summary statistics on socio-economic characteristics that are taken into account in the estimation (age, household size, marital status, education and income).

Cross-sectional averages summarize the expected inflation distribution of a typical individual but hide important heterogeneity across individuals. Assuming that the underlying distribution is simple triangular, Figures 4 and 5 plot the histogram of the means and variances, respectively, of the 3,117 individual-specific distributions of expected inflation. Both figures highlight the considerable heterogeneity in expected inflation distributions. For instance, for 6.7 percent of individuals the mean expected inflation is 0 or negative, for another 20.4 percent it is between 0 and 1 percent, for another 38.7 percent it is between 1 and 2 percent, and for the remaining 34.2 percent the mean expected inflation is higher than 2 percent. The cross-sectional distribution of variances is also heterogeneous, with roughly 13 percent of respondents exhibiting zero variance in their expected inflation distribution (i.e., they do not report any uncertainty about future inflation).

\section{Empirical results}

\subsection{Regression analysis}

Before moving to regression analysis, we plot the mean of expected inflation and its variance by bins of trust in the ECB. The results are shown in Figures 6 and 7, respectively. The figures 
suggest a negative association between trust in the ECB and both expected inflation and the variance of expected inflation.

Since the patterns of Figures 6 and 7 may be influenced by other confounding variables, we estimate the relation between average expected inflation or the variance of expected inflation and reported trust in the ECB by estimating the following equation:

$$
g_{i}\left(\pi_{i}^{e}\right)=\alpha+\beta \text { trust_ECB } B_{i}+\gamma \boldsymbol{X}_{i}+\varepsilon_{i}
$$

where $g$ is a function denoting either mean or variance of expected inflation $\pi^{e}$ deduced from a simple triangular or split triangular distribution and taking individual-specific values. Variables in $\boldsymbol{X}$ include demographics, such as age (by means of a second order polynomial) and gender of the respondent, whether (s)he has a partner, size of the household, whether the respondent is a high school graduate or has a college degree, and household income. Finally, we include a survey wave dummy to take into account country-wide conditions (e.g., actual past or current inflation and GDP growth) as well as region fixed effects that control for economic developments at the regional level.

To reduce the influence of outliers, we winsorize the mean and variance of expected inflation at the top and bottom 1 percent of the observations; that is, we set the values of those observations equal to those at the $99^{\text {th }}$ and $1^{\text {st }}$ percentiles, respectively. We also use Huber-White robust standard errors clustered at the household level to take into account that for some households, multiple members can participate in the survey.

First, we estimate (1) for mean expected inflation using OLS. Results are shown in the columns 1 and 2 of Table 2. We find a negative association between trust in the ECB and average inflation expectations that is statistically significant at the 1 percent level. The OLS coefficient of trust in the ECB is equal to 0.055 percentage points, which implies that a one standard deviation 
increase in trust (equal to 2.16) is associated with a reduction in expected inflation of 0.12 percent, which corresponds to 7 percent of the sample average of expected inflation. As we show below, however, the average response obtained by OLS is not uniform across different percentiles of the expected inflation distribution.

Household size is negatively associated with higher inflation expectations. ${ }^{13}$ This may reflect the fact that households with more than one member include several potential shoppers who may in turn be more efficient in identifying cheaper products and services, make better deals, or reduce per unit cost by purchasing larger quantities. The coefficients of other demographic variables are not statistically different from zero.

Next, we use an IV approach to address endogeneity problems that may affect the OLS estimates of equation (1), and which could arise due to omitted variables and/ or reverse causality. Finding valid instruments in our context requires finding variables that correlate with trust in the $\mathrm{ECB}$, but do not have a direct association with inflation expectations. The latter condition precludes the use as instruments of variables that may be correlated with institutional or economic knowledge, such as own experience with retail banking services or credit card fraud, as these may have an independent impact on inflation expectation formation. Instead, we exploit variation in the component of trust in the ECB that relates to social capital. The latter typically reflects prevailing social values and tends to be resilient to temporary variations in financial conditions.

Respondents in our survey report the frequency they have been cheated by a plumber, builder, car mechanic or other repair person over the past five years. Roughly one out of five respondents report having been cheated by a repair person at least once. The identifying assumption

\footnotetext{
${ }^{13}$ Fritzer and Rumler (2015) report a similar finding for Austrian households.
} 
is that those who have been cheated tend to trust less, and that part of this mistrust carries over to the trust they show in institutions. Cheating experiences on some common everyday exchanges are arguably exogenous to own actions, so that instrument validity rests upon the assumption that exposure to such incidents does not have a direct impact (i.e., other than through trust in the ECB) on individuals' inflation expectations.

To increase the efficiency of our estimates and generate overidentifying restrictions, we also use as an instrument the reported trust in other people. Trust in other people has a strong intergenerational component that consists of inherited social norms. Thus, it is likely to respond less to contemporaneous economic and personal conditions than trust attached to financial institutions (see Tabellini, 2010 and Stevenson and Wolfers, 2011). Accordingly, we assume that general trust in other people is likely to influence inflation expectations only through institutional trust in the ECB.

The IV results are shown in columns 3 and 4 of Table 2 . The F-test statistic from the first stage regressions is equal to about 86 , which suggests that the instruments are quite strong (results are shown in Online Appendix Table A.1). In addition, both instruments are correlated with trust in the ECB in an expected way. Moreover, a test of overidentifying restrictions (Hansen's J-test) fails to reject the null hypothesis of joint instrument validity with high confidence. Hence, we find no evidence of consistency problems in the IV estimates. Finally, a Hausman test of the endogeneity of the variable of interest, i.e., trust in the ECB, has a p-value equal to 0.046 , which implies that one can marginally reject the null of exogeneity of trust in the ECB at the 5 percent significance level, and thus that IV estimation is likely advisable.

The IV estimate of the effect of trust in the ECB on expected inflation is -0.17 percentage points, that is, somewhat larger in absolute value than the OLS one. The IV estimate implies that 
an increase in trust in the ECB of one standard deviation reduces expected inflation by 0.38 percentage points, which is 22 percent of the sample mean. The larger absolute value of the IV estimate compared to the OLS one could be due to the presence of unobserved variables that affect positively both trust in the ECB and inflation expectations, thus leading to an algebraically larger (i.e., less negative, but smaller in absolute value) OLS estimate. Such unobservable variables could include, for instance, expectations about unemployment or the general state of the economy. Alternatively, the difference between OLS and IV estimates could be due to the fact that in the presence of a heterogeneous effect of trust in the ECB this estimate represents a local average treatment effect, that is, the effect of trust in the ECB on inflation for those who change their trust in the ECB due to changes in the instrument values. On the other hand, the OLS estimate represents the overall average treatment effect.

Having examined the role of trust in the ECB on average inflation, we focus next on the role of trust on inflation uncertainty. Recall that the survey design allows us to deduce a measure of uncertainty about inflation that is individual-specific. That is, we can estimate a version of equation (1) in which the dependent variable represents the individual-specific expected variance of inflation. As it was the case for the expected inflation, its variance is calculated using a simple triangular distribution.

OLS estimates are reported in columns 5 and 6 in Table 2. We find that a higher trust in the ECB leads to a lower variance of the expected inflation distribution. The effect is precisely estimated (p-value $<0.01)$ and implies that a one standard deviation increase in trust in the ECB reduces inflation uncertainty by about 30 percent of its sample mean.

The corresponding IV estimate (shown in columns 7-8 of Table 2) is again precisely estimated (p-value $<0.05$ ) and implies that a one standard deviation increase in the ECB reduces 
inflation uncertainty by about 50 percent of its sample mean. Once more, the J-test of overidentifying restrictions clearly indicates that the null hypothesis of joint instrument validity cannot be refuted. The Hausman test for endogeneity suggests that the null cannot be rejected. Based on these results, the preferred estimates are those derived using standard OLS.

\subsection{Quantile Regressions}

Results thus far suggest that higher trust in the ECB lowers inflation expectations on average. Nevertheless, this effect may not be symmetric across the distribution of expected inflation, that is, it might differ between those who have high and those who have low inflation expectations. In fact, the negative average estimated effect may simply reflect the public view that central banks are primarily concerned about actual inflation exceeding target inflation, and therefore are committed to raising interest rates to restrain inflation. That is, central banks have traditionally built their reputation as safeguards of price stability in situations when inflation tends to exceed their medium-term target. Consequently, a high level of public trust in the ECB could reflect trust in the ECB's commitment and ability to fight high inflation and thereby induces lower inflation expectations. ${ }^{14}$

Results also show that trust in the ECB significantly lowers inflation uncertainty, suggesting that trust may induce a form of anchoring of inflation expectations. We shed more light on this important policy issue by examining whether trust in the ECB contributes to anchoring of expectations around the ECB's target for an inflation below, but close to, 2 percent. To that effect,

\footnotetext{
${ }^{14}$ The explanation that public trust in the ECB responds slowly to contemporaneous economic conditions is consistent with the important role of social capital in shaping trust in institutions (since social capital consists of a large, slowmoving, inherited component of social values and norms; see Tabellini, 2010).
} 
we estimate a series of Quantile Regressions (QR) to evaluate the effect of trust in the ECB across various percentiles of the expected inflation distribution.

Figure 8 plots the estimates and associated 95 percent confidence intervals of the effect of trust in the ECB derived from QR evaluated at every five quantiles of the conditional expected inflation distribution (the respective estimates are reported in Online Appendix Table A2). The figure also plots the OLS estimate and confidence band from the baseline specification discussed above. The vertical line is drawn at the percentile of the expected inflation distribution that corresponds to a 2 percent inflation, that is, the ceiling of the medium-term ECB target.

The QR estimates imply that trust in the ECB raises inflation expectations among individuals with low inflation expectations. In particular, a one standard deviation increase in trust has a positive and strongly statistically significant effect at the $10^{\text {th }}$ and $20^{\text {th }}$ quantiles of the expected inflation distribution (corresponding to 0.35 percent and 0.75 percent expected inflation, respectively), which is equal to 0.16 percent and 0.08 percent, respectively. On the other hand, QR estimates at the sixth and higher deciles display a negative sign, suggesting a progressively stronger negative association of trust in the ECB with inflation expectations among those with higher inflation expectations. Notably, the magnitude of the QR coefficients is stronger on the upper part of the distribution compared to the lower one: a one standard deviation increase in trust in the ECB decreases inflation expectations by 0.28 percent and 0.44 percent at the $80^{\text {th }}$ and $90^{\text {th }}$ percentiles of the expected inflation distribution, respectively.

Finally, QR estimates in the middle part of the expectation distribution are not statistically significant. This part of the distribution includes those who have inflation expectation around 2 percent (denoted by the vertical line), which implies that those who have expectations already aligned with the ECB target change them very little when their trust in the ECB increases. 
Taken together, results from QR point into the role that trust in the ECB has in anchoring consumers' inflation expectations around the ECB's inflation target. In addition, the fact that estimated effects are stronger among those with high inflation expectations suggests that higher trust in the ECB can be more effective in lowering high inflation expectations than raising low inflation expectations. This finding may be a cause for concern in circumstances like those of the recent past, in which inflation in the euro area was well below the ECB's medium-term target.

We also use an IV approach to the QR estimates, using the same two instruments employed earlier in standard IV. Available IV methods for QR require some modifications of the original specification. In particular, both the trust in the ECB variable and our two instruments have to be redefined as binary variables. Hence, the modified trust in the ECB variable is equal to zero for values of trust below 7, while it is equal to 1 for values higher than or equal to 7 . This implies that a change from 0 to 1 in the modified trust in the ECB variable corresponds to a change of about 5 units (or 2.3 standard deviations) in the original variable.

The IV QR estimates for various percentiles are shown in Figure 9, and also in Online Appendix Table A2. The estimated coefficients are larger in absolute terms compared to the respective ones from standard $\mathrm{QR}$, as they reflect a much larger underlying change in the trust in the ECB variable. Moreover, IV QR estimates suggest a similar pattern for the role of trust in the ECB across percentiles of the expected inflation distribution to the one derived using standard QR estimates: the results at the upper part of the expectation distribution are quite stronger than those at the lower part, which are statistically significant at percentiles below the $10^{\text {th }}$ one.

\section{Robustness checks}


In this section we examine whether our baseline results pick up the effect of some alternative factors that may influence inflation expectations and its uncertainty. ${ }^{15}$ Moreover, we report few additional robustness checks.

One potential channel through which trust in the ECB can influence inflation expectations is through the knowledge about the ECB's objectives. Earlier research has found a positive correlation between trust in the ECB and knowledge about the ECB (Ehrmann et al., 2013). More broadly, general economic knowledge is likely to influence economic expectations (Christensen et al., 2006). To that effect, we investigate whether specific knowledge of the ECB's objectives in particular, or economic literacy in general, influence inflation expectations as well as the estimated effect of trust in the ECB.

To measure knowledge about the ECB's objectives we ask respondents six true-false questions about these objectives and construct an index representing the number of correct responses (see Online Appendix A.1 for the wording of these questions). ${ }^{16}$ A correlation analysis shows that knowledge and trust are positively associated. Moreover, descriptive statistics results suggest that knowledge on the ECB goals is not broad based, in line with the findings of Van der Cruijsen et al. (2015). In fact, in most of questions, around 40 percent of respondents report that they do not know the answer. The average number of correct answers is 3.04 , out of a maximum score of 6 . Nevertheless, 42 percent of respondents correctly indicate that that an inflation rate below, but close to, 2 percent is a goal of the ECB. ${ }^{17}$

\footnotetext{
${ }^{15}$ Detailed results are available from the authors upon request.

${ }^{16}$ Possible answers include a "do not know" option, which we consider to be equivalent to an erroneous response.

${ }^{17}$ This high number of correct responses may also reflect the fact that the ECB has set an explicit numerical inflation target.
} 
Having an individual measure of institutional knowledge about the ECB allows us to assess whether reported trust in the ECB mainly reflects perceived credibility of the institution or simply knowledge about its role. Before discussing results from formal regression analysis, we note that if responses to the trust in the ECB question reflected credibility rather than knowledge, respondents would report similar trust towards the DNB. Being part of the euro system, the DNB is likely to have similar credibility as the $\mathrm{ECB}$, but obviously it does not have a national inflation mandate anymore. Indeed, responses to the trust in the ECB question are highly correlated with those on a similar question we have asked about trust in the DNB (the correlation is 0.85 , and significant at the 1 percent level), which suggests that respondents answer the relevant questions having institutional credibility in mind.

To assess how institutional knowledge affects our results, we add the index of the number of correct questions as an additional covariate to the baseline specification. OLS and IV results, both for expected inflation and variance of inflation expectations, are virtually unchanged. Thus, while knowledge and trust are positively correlated, our results suggest that the institutional credibility aspect of the trust in the ECB that affects inflation expectations over and above knowledge about the ECB goals.

We further examine the role of knowledge by using information on whether respondents answer correctly the questions on the ECB's numerical inflation target. In particular, we distinguish between two groups of respondents. The "has a clue" group consists of those answering correctly the ECB 2 percent inflation target question as well as at least three other questions (out of the six in total). The "no clue" group consists of those not knowing about the 2 percent inflation target and 
failing to answer correctly three or more questions. ${ }^{18}$ When we re-estimate our baseline models (i.e., those shown in Table 2 and QR) we do not find significant differences in the implied effect of trust in the ECB on inflation expectations between the two groups.

These results are in line with our earlier findings of an independent influence of the institutional credibility on inflation expectations over and above knowledge about the ECB's objectives. With respect to the group that knows about the ECB's numerical inflation target, our findings imply that trusting the central bank can anchor their inflation expectations around it, as they most likely view deviations from the target as temporary ones. As regards the group that does not know about the central bank numerical inflation target, QR results again suggest some anchoring at a broader range around 2 percent, possibly because inflation at this range is compatible with the notion of price stability that this group has. Indeed, responses from a separate survey show that three out of four respondents think that it is most favorable for the Dutch economy if in each year the general level of prices remains stable or increases slightly.

Second, we measure respondents' financial literacy as regards some basic economic concepts using three standard questions extensively used in the related literature (see Lusardi and Mitchell, 2014). When including financial literacy in our specifications, the estimated effects of trust in the ECB on inflation expectations are once again unchanged.

A third factor that may correlate with trust in the ECB and/ or inflation expectations is individual optimism. To this end, we first construct an indicator of optimism by taking the difference between subjective life expectancy (i.e., self-reported probability to survive upon age

\footnotetext{
${ }^{18}$ Note that the additional restriction of answering at least three other knowledge questions removes from the "has a clue" group clueless respondents whose correct answer that the ECB aims at a price level below but close to 2 percent is due to a guess.
} 
65,80 or 90 , depending on the current age) and objective life expectancy (by gender and age) in official mortality tables (see also Puri and Robinson, 2007, who utilize a similar measure of optimism). In all cases the coefficient of trust in the ECB is hardly affected. ${ }^{19}$ Furthermore, we add an alternative measure of optimism in our specification using information from a self-reported measure of optimism. ${ }^{20}$ Once more, the estimated effect of trust in the ECB remains unaffected.

Overall, the estimates suggest that trust in the ECB has an effect on economic expectations even controlling for the effect of knowledge about the ECB's functions, financial literacy, and optimism.

Trust in the ECB, and more precisely the institutional credibility or social capital component of trust, may reflect beliefs and values shared by individuals living in the same area. Therefore, we examine whether our baseline results are likely affected by unobserved regional heterogeneity, including possible regional differences in trust in the ECB. To this end, we reestimate our baseline models after accounting for regional fixed effects at the level of the twelve Dutch provinces (which represent the most detailed regional classification available in our data). Results remain virtually unchanged. In addition, we re-estimate these models by clustering the standard errors at the province level to allow for possible within province error dependence. Clustering at such an aggregate level, leaves our baseline estimates on trust in the ECB (shown in Table 2) statistically significant at 5\%.

\footnotetext{
${ }^{19}$ Estimated effects of the trust in the ECB variable remain statistically significant, but the p-value is higher compared to the baseline specification. This is due to the lower number of observations used, as there are missing values of the variable denoting subjective life expectancy.

${ }^{20}$ Respondents indicate to which extent they agree (on a scale from 1 to 5) with the following statement: "Overall, I expect more good things to happen to me than bad things". Guiso et al. (2008) use the same measure to disentangle the effect of trust on stock investing from that of optimism.
} 
As already mentioned, our estimation sample is smaller than the original one, mainly due to missing observations in inflation and/ or trust in the ECB questions. To investigate whether our results are affected by these missing observations, we impute missing values for these two key variables. Adding imputed values increases our estimation sample to 4,248 observations (from 3,055 observations in the baseline estimation using the simple triangular distribution). Results from this larger sample, based on OLS and QR estimates of the relationship between trust in the ECB and inflation expectations, are similar to those we present in Section 4 (results on expected inflation and its variance are reported in Online Appendix Table A3).

As a final robustness check, we estimate the baseline specification replacing the simple triangular distribution with the split one. We find that the results on inflation expectations, uncertainty and anchoring remain unchanged (see Online Appendix Table A4 for these results). Similarly, results are robust to assuming alternative distributional forms, such as uniform and split uniform distributions.

\section{GDP growth}

The broader objectives of monetary policy are not limited to price stability but include also other macroeconomic variables, among which economic growth is of course prominent. Hence, it is instructive to examine whether trust in the ECB impacts also individual expectations regarding economic growth and economic fluctuations (e.g., GDP growth rate volatility). To elicit the distribution of expected GDP growth, we ask individuals the same sequence of three questions as for inflation: the minimum and maximum expected growth rate, and the chance that growth exceeds the midpoint of the reported minimum and maximum. 
As is the case with inflation expectations, we plot the mean of expected growth and its variance by bins of trust in the ECB in Figures 10 and 11, respectively. There is a clear positive association between trust in the ECB and individual expectations about economic growth. On the other hand, we find essentially no association between trust in the ECB and the variance of expected growth.

The patterns shown in the two figures are confirmed when we estimate multivariate regressions with expected growth and its variance as dependent variables. Table 3 reports OLS and IV regressions for the mean (columns 1-4) and variance of expected GDP growth (columns 5-8). As is the case with inflation expectations, we cluster Huber-White robust standard errors at the household level, and winsorize the dependent variables at the top and bottom 1 percent of observations. ${ }^{21}$ The test statistics for the IV regressions suggest again that the instruments are strong and that one cannot reject instrument exogeneity. At the same time, the Hausman test does not reject the null hypothesis that trust in the ECB is exogenous. Therefore, one could restrict attention to the OLS estimates. Yet, to maintain consistency with our analysis of expected inflation and its variance, we present both OLS and IV results. In any case, both analyses lead to qualitatively similar estimates of the effects of trust in the ECB.

In particular, we find that trust in the ECB increases expected GDP growth. According to the baseline OLS estimate, a one standard deviation higher trust in the ECB implies an increase in expected GDP growth by 17 basis points. The coefficient is statistically significant (at the 1 percent level) and the effect corresponds to 12 percent of the sample mean of expected GDP growth. The corresponding IV estimate is somewhat higher ( 27 basis points, corresponding to 18 percent of the

\footnotetext{
${ }^{21}$ The number of observations is slightly higher as the number of "do not know" responses to the GDP growth questions is lower than for the inflation questions (see also Christensen et al., 2006).
} 
sample mean). In contrast, results in columns 5 to 8 imply that trust has no effect on the uncertainty about expected GDP growth. ${ }^{22}$ As regards other covariates, we find a negative (positive) association between the female dummy and expecting a higher (being more uncertain about the) growth rate. This seems aligned with insights from the cognitive psychology literature on the link between gender and reactions related to anxiety about the future (e.g. Robichaud et al., 2003).

The finding that trust in the ECB affects inflation expectations negatively at the mean, and growth expectations positively, suggests that respondents on average do not associate necessarily higher inflation with higher growth. This could be due to several reasons, including the "Great moderation" period that featured both low inflation and economic prosperity, memories of past stagflation, or experience drawn from other countries, where deep recessions have been accompanied by episodes of high inflation rates.

\section{Summary}

Historically, central banks have paid a lot of attention to inflation expectations formed in financial markets and by professional forecasters. More recently, central banks have shown increased interest in consumer expectations and beliefs because they can help make policy more effective (Bernanke, 2013; Blinder et al., 2008). In this paper, we investigate the extent to which trust in the ECB impacts individuals' expectations and uncertainty about future inflation and induces inflation anchoring at the ECB's inflation target of below, but close to, 2 percent. The

\footnotetext{
${ }^{22}$ We have also estimated a series of QR regressions to examine whether estimates of trust in the ECB display a pattern of anchoring around a specific value of the expected GDP growth distribution. We do not find any evidence for anchoring in this case. QR estimates are always positive and decline across quantiles, suggesting that higher trust in the ECB is associated with higher expected GDP growth, and more so among those with low GDP growth expectations.
} 
empirical evidence draws upon a special questionnaire module introduced in a recent survey of a representative sample of the Dutch population.

A first finding of our analysis is that a high level of trust lowers inflation expectations. This result may be due to the fact that traditionally central banks have been mainly concerned about inflation exceeding their target and communicated to the public their commitment to raise interest rates to restrain inflation. Consequently, a high level of public trust in the ECB is likely to reflect trust in the ECB's commitment and ability to fight high inflation and thereby induces lower inflation expectations on average.

Recently, central banks have been using unconventional policy instruments to cope with a long period of low inflation and near zero interest rates. Based upon a survey among central bank presidents and academic experts, Blinder et al. (2017) argue that these new policy instruments as well as the increased use of communication will permanently remain in the toolkit of central banks. Communication is, among others, important for central banks for anchoring inflation expectations around the target inflation rate and preventing medium term inflation expectations from falling below target.

Our findings are directly related to this desired anchoring of inflation expectations because they indicate that trust in the ECB induces anchoring around the medium term inflation target. Specifically, we show that the effect of trust is not uniform across the distribution of inflation expectations: at the lower end of the distribution, an increase in trust increases inflation expectations, while the opposite is true at the higher end of the distribution of inflation expectations. Estimated effects are particularly strong among respondents having high inflation expectations, suggesting that higher trust in the ECB matters more for lowering high inflation expectations as opposed to increasing low inflation expectations. This finding may be a cause for 
concern in a low interest rate environment, especially as regards the segment of the population with quite low inflation expectations. It suggests that central banks may benefit from effectively communicating their commitment to raise prices towards their target as forcefully as their commitment to fight high inflation in previous times.

In a related vein, we also find that trust in the ECB reduces individual uncertainty about future inflation, thus contributing to public confidence about future price stability and the economy's prospects. ${ }^{23}$ Taken together, our findings suggest that a high level of trust supports the monetary policy of the ECB because it contributes to the anchoring of inflation expectations in the population around the target of below, but close to, 2 percent.

One may argue that it is not the institutional credibility of the ECB that matters for our findings, but rather the knowledge about the tasks and the goals of the ECB (or the knowledge about economic concepts in general). While there is a positive association between knowledge of the ECB goals and trust in the ECB, our results are virtually unaffected when knowledge about the ECB's objectives and financial literacy are taken into account. Hence, it appears that the institutional credibility component of trust in the ECB has an independent influence on inflation expectations.

Finally, our findings suggest that the effectiveness of monetary policy could benefit from investing in the build-up of trust and institutional credibility. In the current environment of low interest rates, where standard monetary policy measures are difficult to implement and likely to be less effective, such an investment is likely to be particularly beneficial.

\footnotetext{
${ }^{23}$ From a monetary policy perspective, reduced uncertainty strengthens anchoring around a medium term inflation target and induces equilibrium prices to converge faster towards this target (Bernanke, 2013). From a broader perspective, reduced uncertainty is beneficial for economic welfare. It helps households' financial planning and lowers the need for precautionary saving (see Christelis et al., 2019, on the effect of consumption uncertainty on the latter).
} 


\section{References}

Armantier O., W. Bruine de Bruin, G. Topa, W. van der Klaauw, and B. Zafar (2015), "Inflation expectations and behavior: Do survey respondents act on their beliefs?," International Economic Review, 56, 505-536.

Bernanke, B. (2013), "Communication and Monetary Policy" speech delivered at "National Economists Club Annual Dinner" held in Washington DC. (https://www.federalreserve.gov/newsevents/speech/bernanke20131119a.pdf)

Blinder, A., M. Ehrmann, M. Fratzscher, J. de Haan, and D. Jansen (2008), "Central bank communication and monetary policy: A survey of theory and evidence," Journal of Economic Literature, 46(4), 910-945.

Blinder, A., M. Ehrmann, J. de Haan, and D. Jansen (2017), "Necessity as the mother of invention: Monetary policy after the crisis," Economic Policy, 32(92), 707-755.

Bursian, D., and S. Fürth (2015), "Trust Me! I am a European Central Banker," Journal of Money, Credit and Banking, 47(8), 1503-1530.

Carvalho, C., and F. Nechio (2014), "Do people understand monetary policy?," Journal of Monetary Economics, 66, 108-123.

Christelis, D., Georgarakos, D., T. Jappelli, and M. van Rooij (2019), "Consumption uncertainty and precautionary saving," forthcoming in Review of Economics and Statistics.

Christensen, C., P. van Els, and M. van Rooij (2006), "Dutch households' perceptions of economic growth and inflation," De Economist, 154, 277-294.

Coibion, O., and Y. Gorodnichenko (2015), "Is the Phillips curve alive and well after all? Inflation expectations and the missing disinflation," American Economic Journal: Macroeconomics, 7(1), 197-232.

D'Acunto, F., D. Hoang, and M. Weber (2016), "Unconventional fiscal policy, inflation expectations, and consumption expenditure," CESIFO Working Paper, 5793.

Dominitz, J., and C. Manski (1997), "Using expectations data to study subjective income expectations," Journal of the American Statistical Association, 92, 855-67.

Ehrmann, M., and M. Fratzscher (2005), "How should central banks communicate?," ECB Working Paper, 557.

Ehrmann, M., M. Soudan, and L. Stracca (2013), “Explaining European Union citizens' trust in the European Central Bank in normal and crisis times," Scandinavian Journal of Economics, 115(3), 781-807.

Ekinci, M., S. Kalemli-Özcan, and B. Sorensen (2009), "Financial integration within E.U. countries: The role of institutions, confidence, and trust", in: Clarida, R., and F. Giavazzi (eds.), NBER International Seminar on Macroeconomics 2007, Chicago University Press, Chicago, pp. 325-391.

Fernandez, R. (2011), "Does culture matter", in: Benhabib, J., M. Jackson, and A. Bisin (eds.). Handbook of Social Economics, vol. 1A, North-Holland, The Netherlands, pp. 481-510.

Fritzer, F., and F. Rumler (2015), "Determinants of inflation perceptions and expectations: An empirical analysis for Austria," Monetary Policy and the Economy, Oesterreichische Nationalbank, 1, 11-26.

Georgarakos, D., and G. Pasini (2011), "Trust, sociability, and stock market participation," Review of Finance, 15(4), 693-725.

Gerlach-Kristen, P., and R. Moessner (2014), "Inflation expectations, central bank credibility and the global financial crisis," Swiss Journal of Economics and Statistics, 150(2), 55-87. 
Guiso, L., Jappelli, T., and L. Pistaferri (2002), “An empirical analysis of earnings and employment risk," Journal of Business and Economic Statistics, 20, 241-253.

Guiso, L., P. Sapienza, and L. Zingales (2004), "The role of social capital in financial development," American Economic Review, 94, 526-556.

Guiso, L., P. Sapienza, and L. Zingales (2006), "Does culture affect economic outcomes?," Journal of Economic Perspectives, 20(2), 23-48.

Guiso, L., P. Sapienza, and L. Zingales (2008), “Trusting the stock market,” Journal of Finance, 63(6), 2557-2600.

Guiso, L., Jappelli, T., and M. Padula (2013), "Pension wealth uncertainty," Journal of Risk and Insurance, 80, 1057-1085.

Gürkaynak, R., A. Levin, and E. Swanson (2010), "Does inflation targeting anchor long-run inflation expectations? Evidence from long-term bond yields in the U.S., U.K. and Sweden," Journal of the European Economic Association, 8(6), 1208-1242.

Kril, Z., D. Leiser, and A. Spivak (2016), "What determines the credibility of the central bank of Israel in the public eye?," International Journal of Central Banking, 12(1), 67-93.

Kliesen, K. (2015), "How accurate are measures of long-term inflation expectations?," Federal Reserve Bank of Saint Louis Economic Synopses, 9, 1-3.

Knack, S., and P. Keefer (1997), "Does social capital have an economic payoff? A cross-country investigation," Quarterly Journal of Economics, 112(4), 1251-1288.

Kumar, S., H. Afrouzi, O. Coibion, and Y. Gorodnichenko (2015), "Inflation targeting does not anchor inflation expectations: Evidence from firms in New Zealand," Brookings Papers on Economic Activity, Fall, 151-225.

Kydland, F., and E. Prescott (1977), "Rules rather than discretion: The inconsistency of optimal plans," Journal of Political Economy, 85(3), 473-492.

Lusardi, A., and O. Mitchell (2014), "The economic importance of financial literacy: Theory and evidence," Journal of Economic Literature, 52(1), 5-44.

Malmendier, U., and S. Nagel (2016), "Learning from inflation experiences," Quarterly Journal of Economics, 131(1), 53-87.

Puri, M., and D. Robinson (2007), "Optimism and economic choice," Journal of Financial Economics, 86, 71-99.

Robichaud, M., M. Dugas, and M. Conway (2003), "Gender differences in worry and associated cognitive-behavioral variables," Journal of Anxiety Disorders, 17(5), 501-516.

Stevenson, B., and J. Wolfers (2011), "Trust in public institutions over the business cycle," American Economic Review, 101(3), 281-87.

Tabellini, G. (2010), "Culture and institutions: Economic development in the regions of Europe," Journal of the European Economic Association, 8(4), 677-716.

Van der Cruijsen, C., J. de Haan, and D. Jansen (2016), "Trust and financial crisis experiences", Social Indicators Research, 127(2), 577-600.

Van der Cruijsen, C., D. Jansen, and J. de Haan (2015), "How much does the public know about the ECB's monetary policy? Evidence from a survey of Dutch consumers," International Journal of Central Banking, 11(4), 169-218.

Wälti, S. (2012), "Trust no more? The impact of the crisis on citizens' trust in central banks," Journal of International Money and Finance, 31, 593-605.

Zak, P., and S. Knack (2001), "Trust and growth,” Economic Journal, 111, 295-321. 
Table 1. Descriptive Statistics

\begin{tabular}{|c|c|c|c|}
\hline Variable & Mean & Median & Std. Deviation \\
\hline Minimum expected inflation level & 1.303 & 1.000 & 1.889 \\
\hline Maximum expected inflation level & 2.699 & 2.000 & 2.743 \\
\hline Probability that the expected inflation level is above & & & \\
\hline $\begin{array}{l}\text { the average of the expected minimum and maximum } \\
\text { values }\end{array}$ & 0.469 & 0.500 & 0.185 \\
\hline Expected inflation & 2.001 & 1.600 & 2.187 \\
\hline Variance of expected inflation & 0.208 & 0.042 & 0.838 \\
\hline Minimum expected growth rate & 0.965 & 1.000 & 1.499 \\
\hline Maximum expected growth rate & 1.967 & 2.000 & 1.782 \\
\hline Probability that the expected growth Rate is above the & & & \\
\hline $\begin{array}{l}\text { average of the expected minimum and maximum } \\
\text { values }\end{array}$ & 0.415 & 0.500 & 0.186 \\
\hline Expected growth rate & 1.465 & 1.500 & 1.520 \\
\hline Variance of expected growth rate & 0.108 & 0.020 & 0.575 \\
\hline Trust in the ECB & 4.769 & 5.0 & 2.163 \\
\hline Age & 50.8 & 51.0 & 16.6 \\
\hline Female householder & 0.452 & 0.0 & 0.498 \\
\hline Household size & 2.488 & 2.0 & 1.252 \\
\hline Has a spouse/partner & 0.747 & 1.0 & 0.435 \\
\hline High school graduate & 0.383 & 0.0 & 0.486 \\
\hline University graduate & 0.309 & 0.0 & 0.462 \\
\hline Household income & $2,721.8$ & $2,450.0$ & $2,004.8$ \\
\hline Number of Observations & 3,117 & & \\
\hline
\end{tabular}

Note. All magnitudes related to the expected inflation and growth rate are expressed in percentage points. 
Table 2. OLS and IV results for expected inflation and its variance

\begin{tabular}{|c|c|c|c|c|c|c|c|c|}
\hline \multirow{4}{*}{ Variable } & (1) & $(2)$ & (3) & (4) & (5) & (6) & (7) & (8) \\
\hline & \multicolumn{4}{|c|}{ Average of expected inflation } & \multicolumn{4}{|c|}{ Variance of expected inflation } \\
\hline & \multicolumn{2}{|c|}{ OLS } & \multicolumn{2}{|r|}{ IV } & \multicolumn{2}{|c|}{ OLS } & \multicolumn{2}{|c|}{ IV } \\
\hline & Coeff. & Std. error & Coeff. & Std. error & Coeff. & Std. error & Coeff. & Std. error \\
\hline Trust_ECB & -0.0552 & $0.0190 * * *$ & -0.1736 & $0.0597 * * *$ & -0.0120 & $0.0030 * * *$ & -0.0210 & $0.0100 * *$ \\
\hline Age & 0.0155 & 0.0152 & 0.0090 & 0.0170 & -0.0040 & 0.0030 & -0.0040 & 0.0030 \\
\hline Age squared & -0.0001 & 0.0001 & -0.0001 & 0.0002 & 0.0000 & 0.0000 & 0.0000 & 0.0000 \\
\hline Female & 0.0041 & 0.0717 & -0.0591 & 0.0812 & 0.0170 & 0.0130 & 0.0090 & 0.0150 \\
\hline Couple & 0.0922 & 0.1013 & 0.0726 & 0.1108 & 0.0080 & 0.0200 & 0.0090 & 0.0210 \\
\hline Household size & -0.1331 & $0.0353 * * *$ & -0.1505 & $0.0401 * * *$ & -0.0170 & $0.0080 * *$ & -0.0220 & $0.0090 * *$ \\
\hline High school graduate & 0.1093 & 0.0989 & 0.1851 & 0.1175 & 0.0010 & 0.0180 & 0.0130 & 0.0210 \\
\hline College graduate & 0.0976 & 0.0929 & 0.2550 & $0.1259 * *$ & 0.0180 & 0.0170 & 0.0400 & $0.0210 *$ \\
\hline $\begin{array}{l}\text { Logarithm of household } \\
\text { net income }\end{array}$ & 0.0066 & 0.0343 & 0.0275 & 0.0340 & -0.0080 & 0.0090 & -0.0040 & 0.0100 \\
\hline constant & 1.5528 & $0.5116 * * *$ & 2.1168 & $0.6219 * * *$ & 0.4700 & $0.1210 * * *$ & 0.4880 & $0.1430 * * *$ \\
\hline Region/ wave dummies & \multicolumn{2}{|c|}{ yes } & \multicolumn{2}{|c|}{ yes } & \multicolumn{2}{|c|}{ yes } & \multicolumn{2}{|c|}{ yes } \\
\hline First-stage $F$ test & \multicolumn{4}{|c|}{86.433} & \multicolumn{4}{|c|}{86.433} \\
\hline Endogeneity test & \multicolumn{4}{|c|}{3.971} & \multicolumn{4}{|c|}{0.974} \\
\hline P value & \multicolumn{4}{|c|}{0.046} & \multicolumn{4}{|c|}{0.324} \\
\hline $\begin{array}{l}\text { Test of overidentifying } \\
\text { restrictions }\end{array}$ & \multicolumn{4}{|c|}{0.766} & \multicolumn{4}{|c|}{0.314} \\
\hline P value & \multicolumn{4}{|c|}{0.381} & \multicolumn{4}{|c|}{0.575} \\
\hline Observations & \multicolumn{2}{|l|}{3,055} & \multicolumn{2}{|l|}{2,632} & \multicolumn{2}{|l|}{3,055} & \multicolumn{2}{|l|}{2,632} \\
\hline
\end{tabular}

Note. This table shows OLS and IV estimation results from models using expected inflation and its variance (both measured in percentage points) as dependent variables. $* * *, * *$ denote statistical significance at $1 \%, 5 \%$ and $10 \%$, respectively. 
Table 3. OLS and IV results for expected growth and its variance

\begin{tabular}{|c|c|c|c|c|c|c|c|c|}
\hline \multirow{4}{*}{ Variable } & (1) & $(2)$ & (3) & (4) & (5) & (6) & (7) & (8) \\
\hline & \multicolumn{4}{|c|}{ Mean of expected growth rate } & \multicolumn{4}{|c|}{ Variance of expected growth rate } \\
\hline & \multicolumn{2}{|c|}{ OLS } & \multicolumn{2}{|r|}{ IV } & \multicolumn{2}{|c|}{ OLS } & \multicolumn{2}{|r|}{ IV } \\
\hline & Coeff. & Std. error & Coeff. & Std. error & Coeff. & Std. error & Coeff. & Std. error \\
\hline Trust in the ECB & 0.0792 & $0.0106 * * *$ & 0.1250 & $0.0347 * * *$ & -0.0010 & 0.0010 & -0.0030 & 0.0050 \\
\hline Age & -0.0104 & 0.0102 & -0.0088 & 0.0107 & -0.0040 & $0.0020 * *$ & -0.0030 & $0.0020 *$ \\
\hline Age squared & 0.0001 & 0.0001 & 0.0001 & 0.0001 & 0.0000 & 0.0000 & 0.0000 & 0.0000 \\
\hline Female & -0.1481 & $0.0433 * * *$ & -0.1950 & $0.0466 * * *$ & 0.0130 & $0.0060 * *$ & 0.0100 & 0.0060 \\
\hline Couple & 0.0336 & 0.0682 & 0.0415 & 0.0707 & 0.0080 & 0.0090 & -0.0010 & 0.0100 \\
\hline Household size & -0.0034 & 0.0283 & -0.0081 & 0.0295 & -0.0030 & 0.0040 & 0.0000 & 0.0040 \\
\hline High school graduate & 0.0520 & 0.0631 & 0.0786 & 0.0692 & -0.0040 & 0.0080 & 0.0010 & 0.0090 \\
\hline College graduate & 0.0738 & 0.0595 & 0.0710 & 0.0745 & 0.0040 & 0.0080 & 0.0120 & 0.0100 \\
\hline $\begin{array}{l}\text { Logarithm of household } \\
\text { net income }\end{array}$ & 0.0220 & 0.0232 & 0.0287 & 0.0243 & 0.0020 & 0.0030 & 0.0040 & $0.0020 * *$ \\
\hline constant & 0.9066 & $0.3309 * * *$ & 0.5269 & 0.3845 & 0.2060 & $0.0540 * * *$ & 0.1780 & $0.0600 * * *$ \\
\hline Region/ wave dummies & ye & & ye & & ye & & ye & \\
\hline First-stage F test & & & 92.332 & & & & 92.332 & \\
\hline Endogeneity test & & & 2.070 & & & & 0.019 & \\
\hline P value & & & 0.150 & & & & 0.890 & \\
\hline $\begin{array}{l}\text { Test of overidentifying } \\
\text { restrictions }\end{array}$ & & & 0.297 & & & & 1.419 & \\
\hline P value & & & 0.586 & & & & 0.234 & \\
\hline Observations & 3,145 & & 2,716 & & 3,145 & & 2,716 & \\
\hline
\end{tabular}

Note. This table shows OLS and IV estimation results from models using the expected growth rate and its variance (both measured in percentage points) as dependent variables. ${ }^{* *}, * *, *$ denote statistical significance at $1 \%, 5 \%$ and $10 \%$, respectively. 
Figure 1. Histogram of the minimum expected inflation level

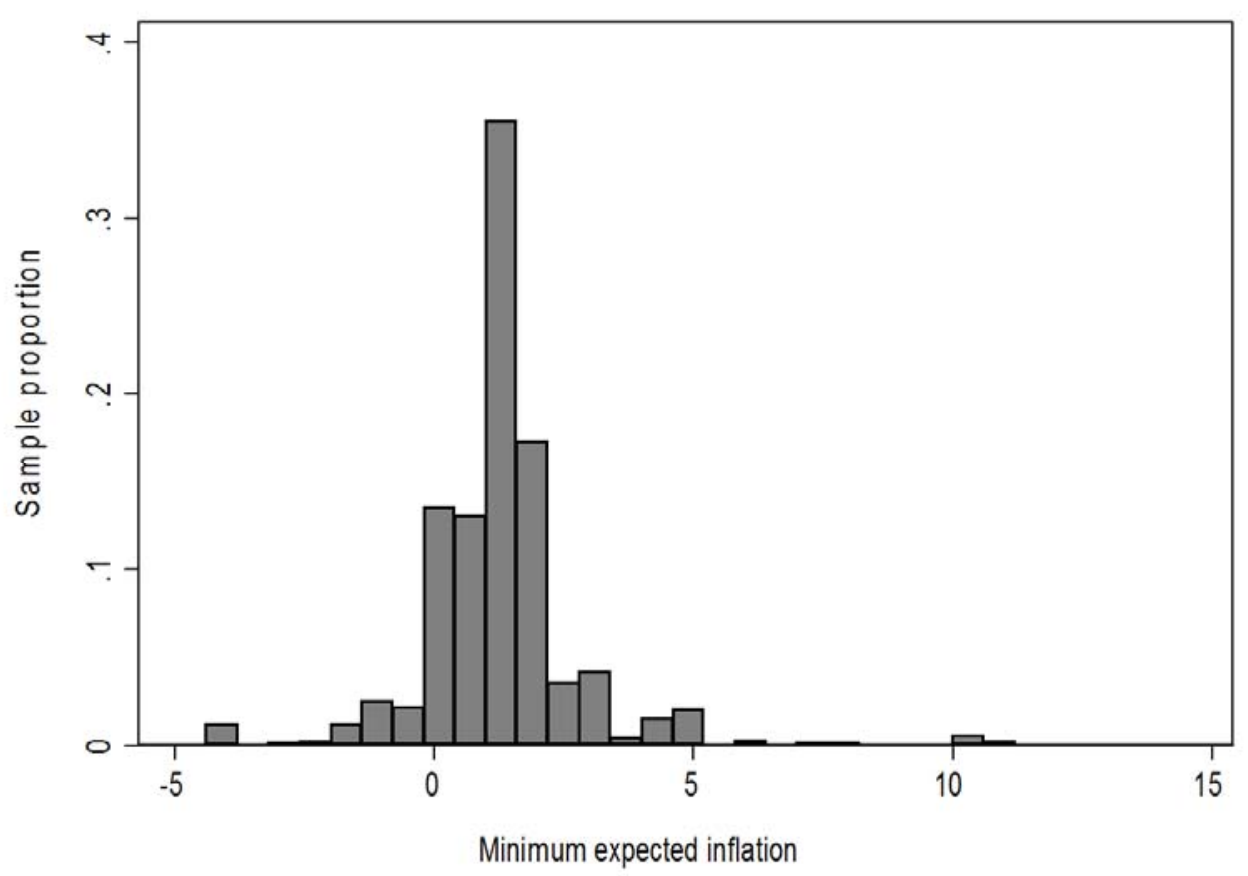

Figure 2. Histogram of the maximum expected inflation level

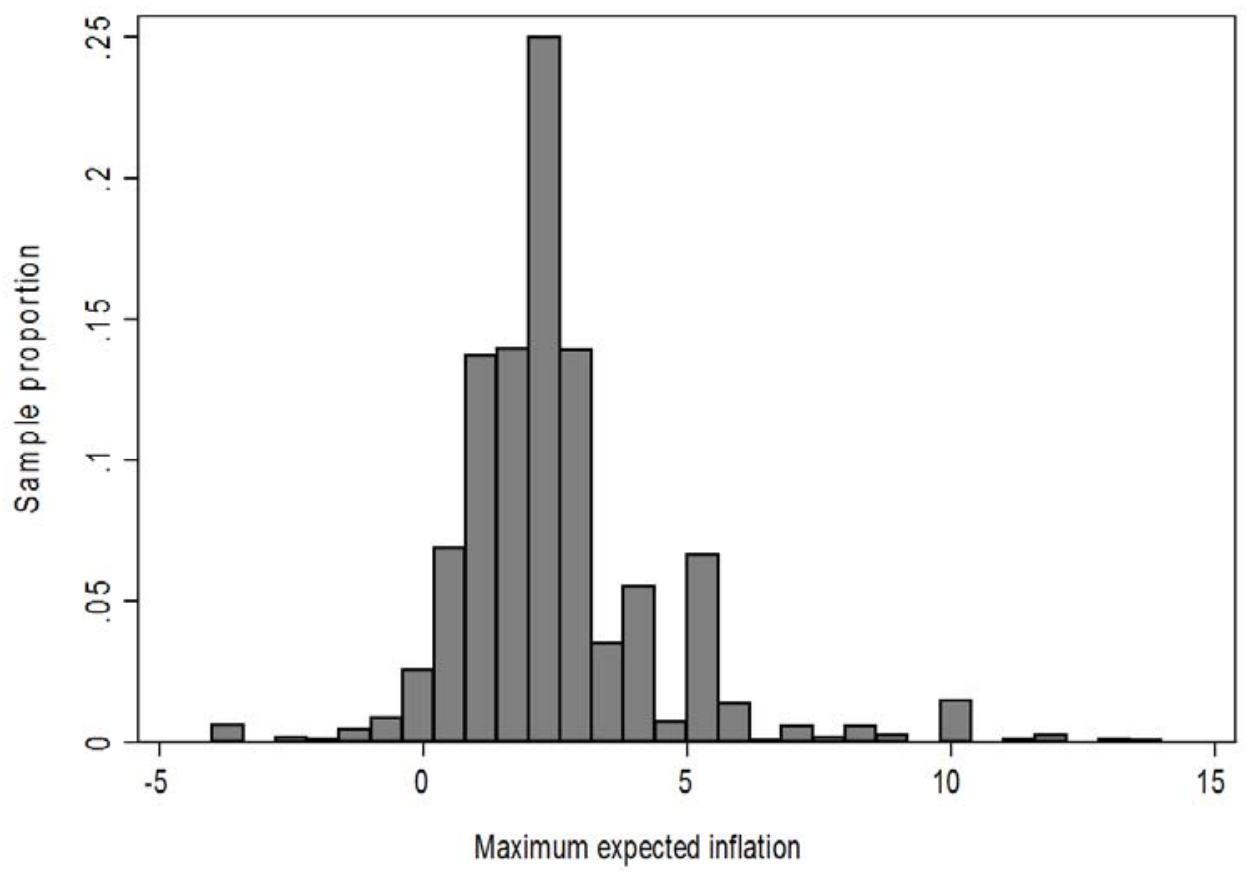


Figure 3. Histogram of the probability that expected inflation is above the average of the expected minimum and maximum values

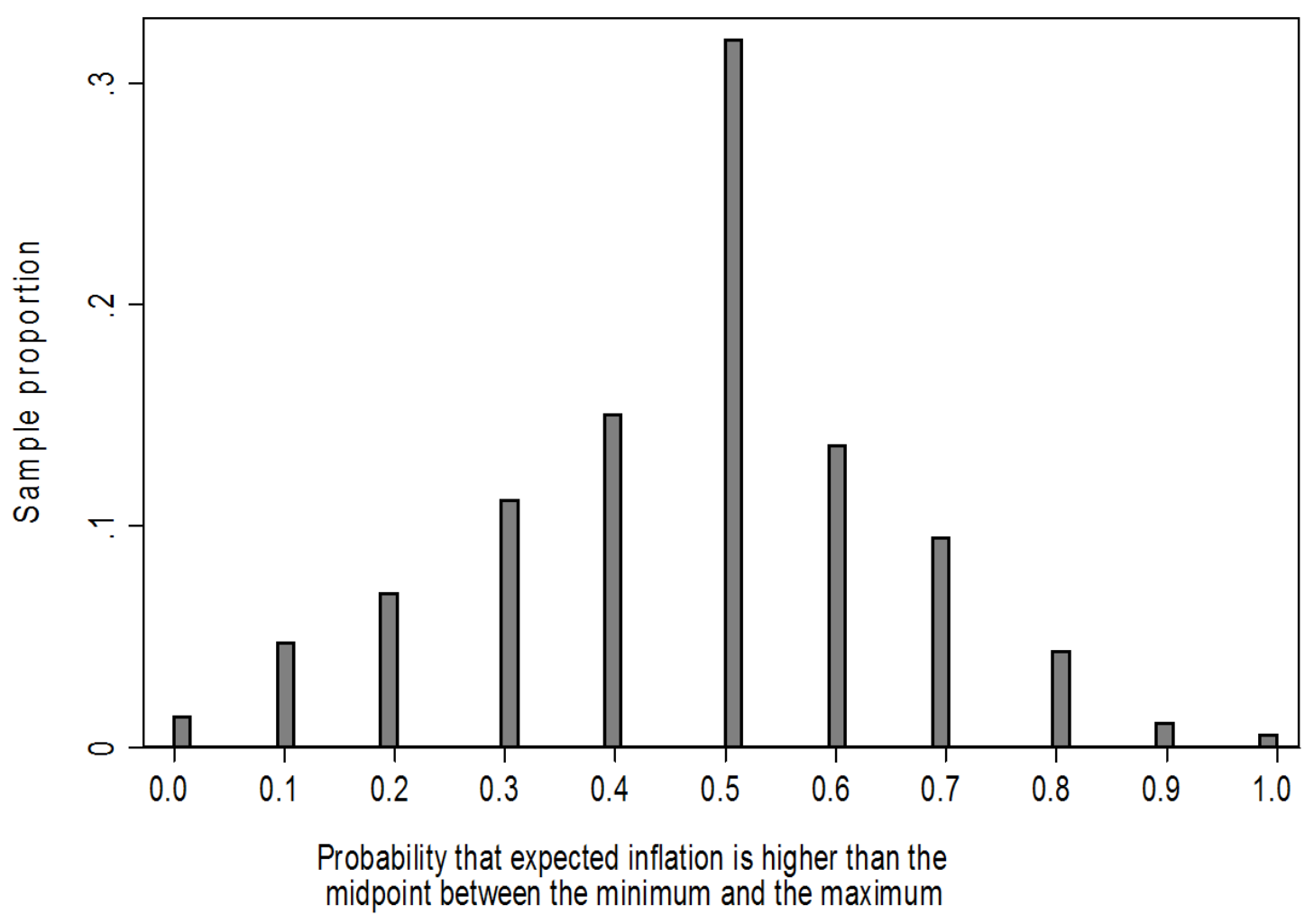


Figure 4. Histogram of the mean of expected inflation

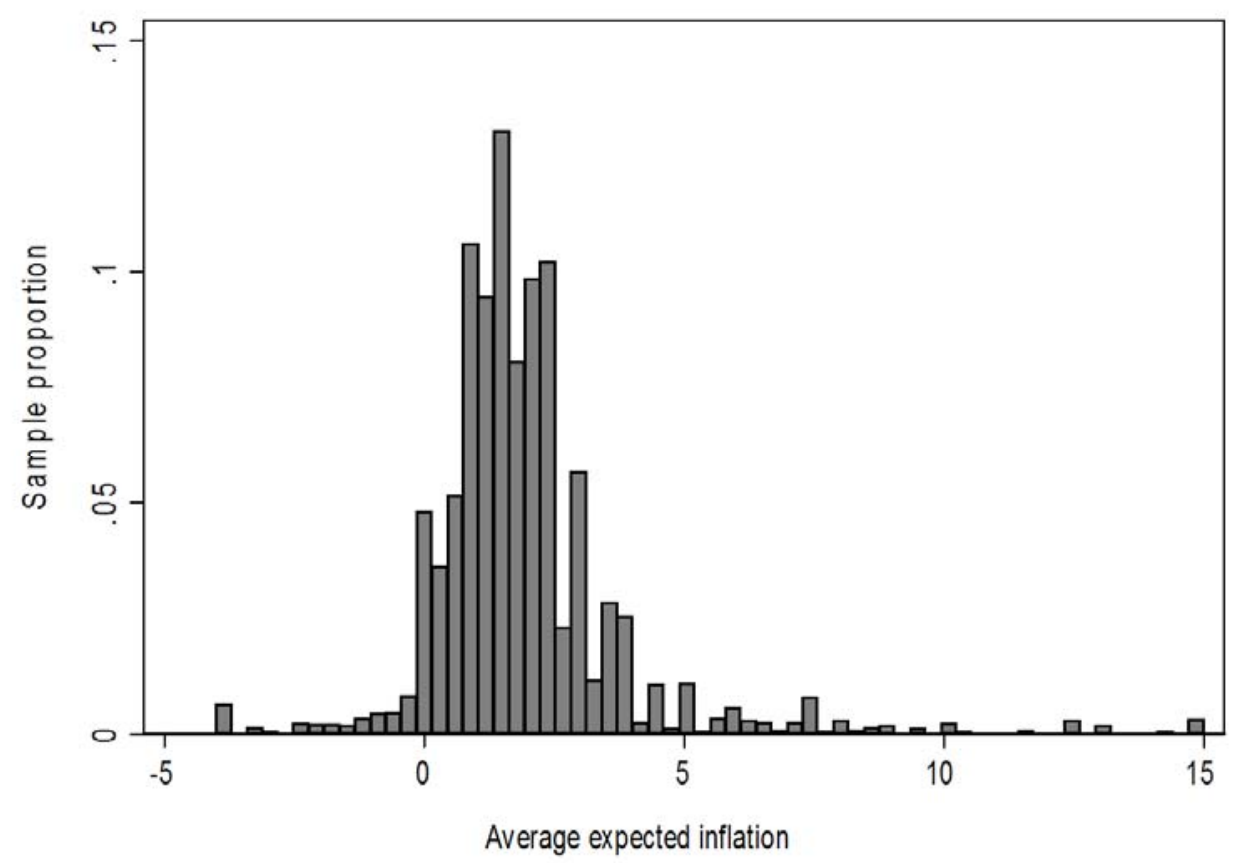

Figure 5. Histogram of the variance of expected inflation

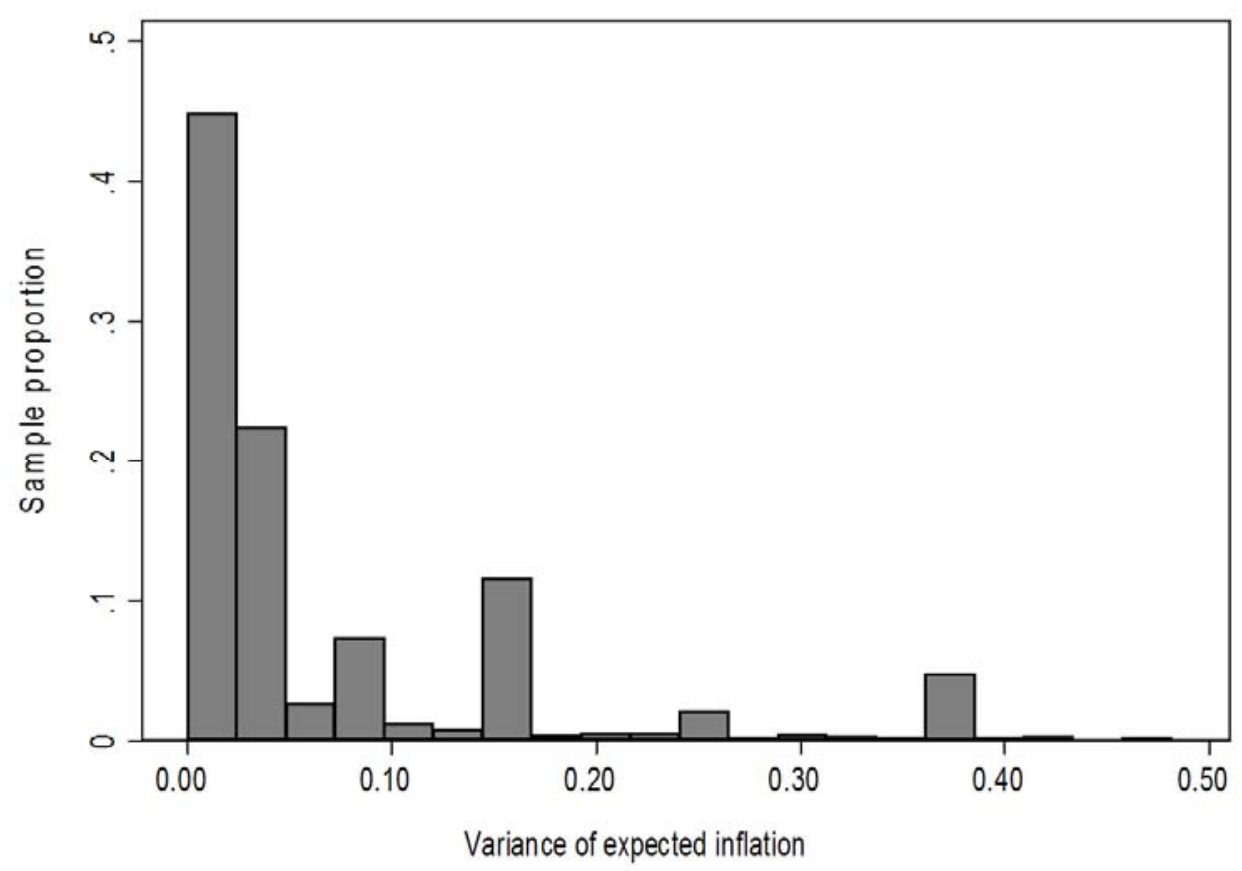


Figure 6. Average expected inflation by levels of trust in the ECB

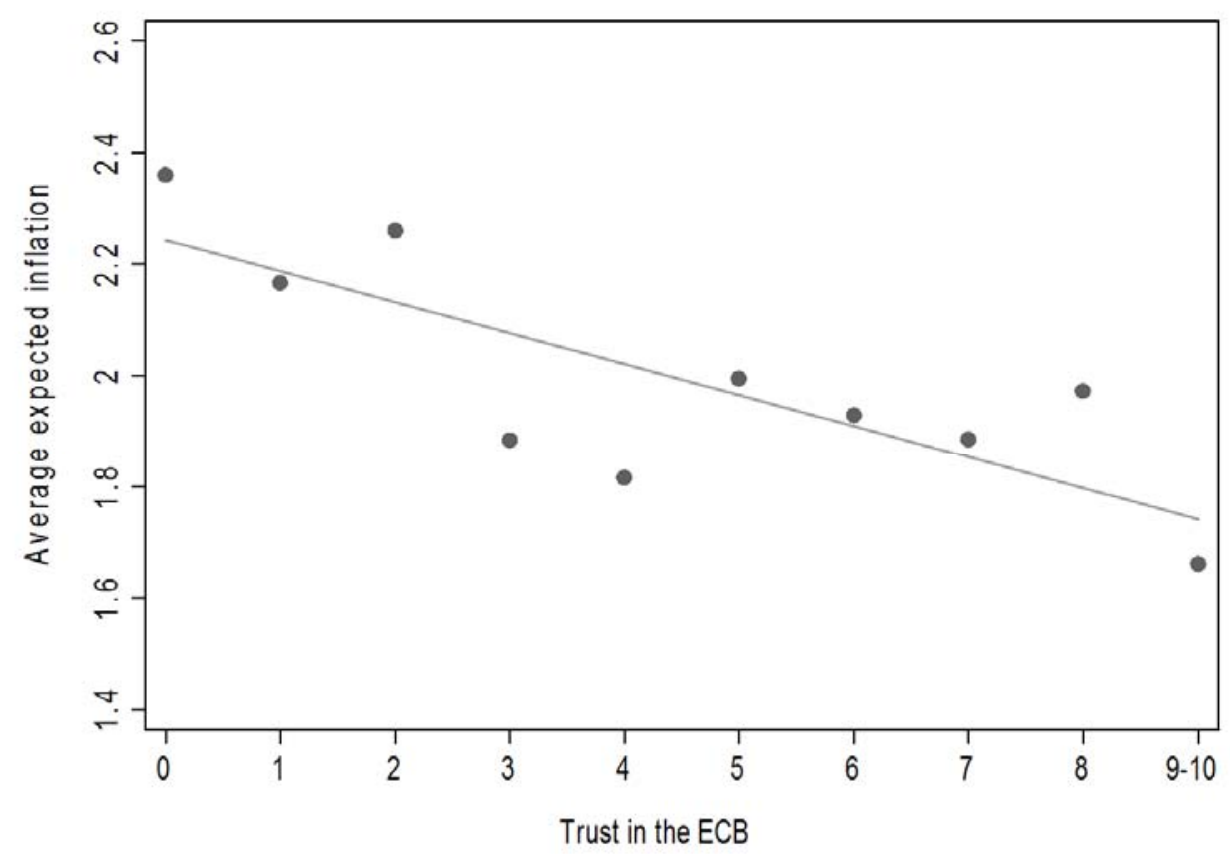

Figure 7. Variance of expected inflation by levels of trust in the ECB

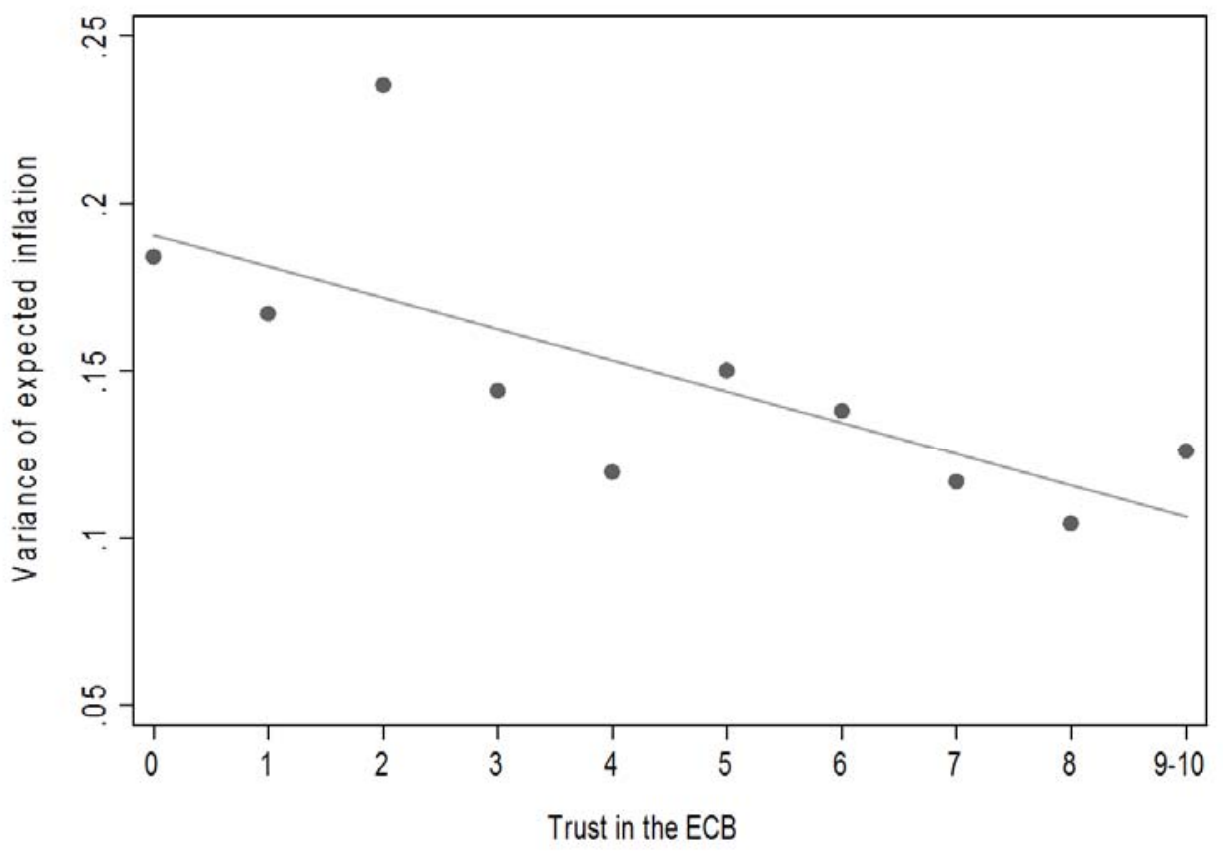


Figure 8. Quantile regression estimates for expected inflation

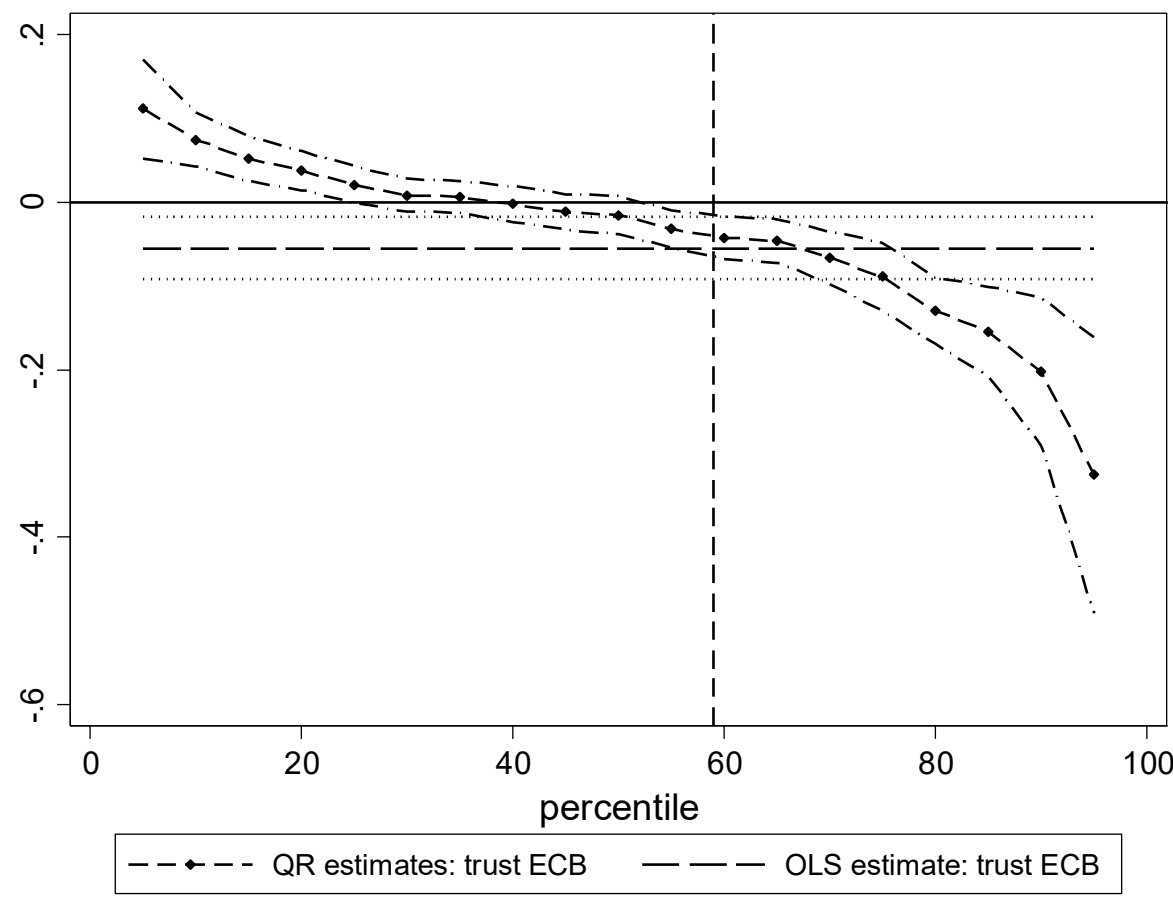

Figure 9. IV quantile regression estimates for expected inflation

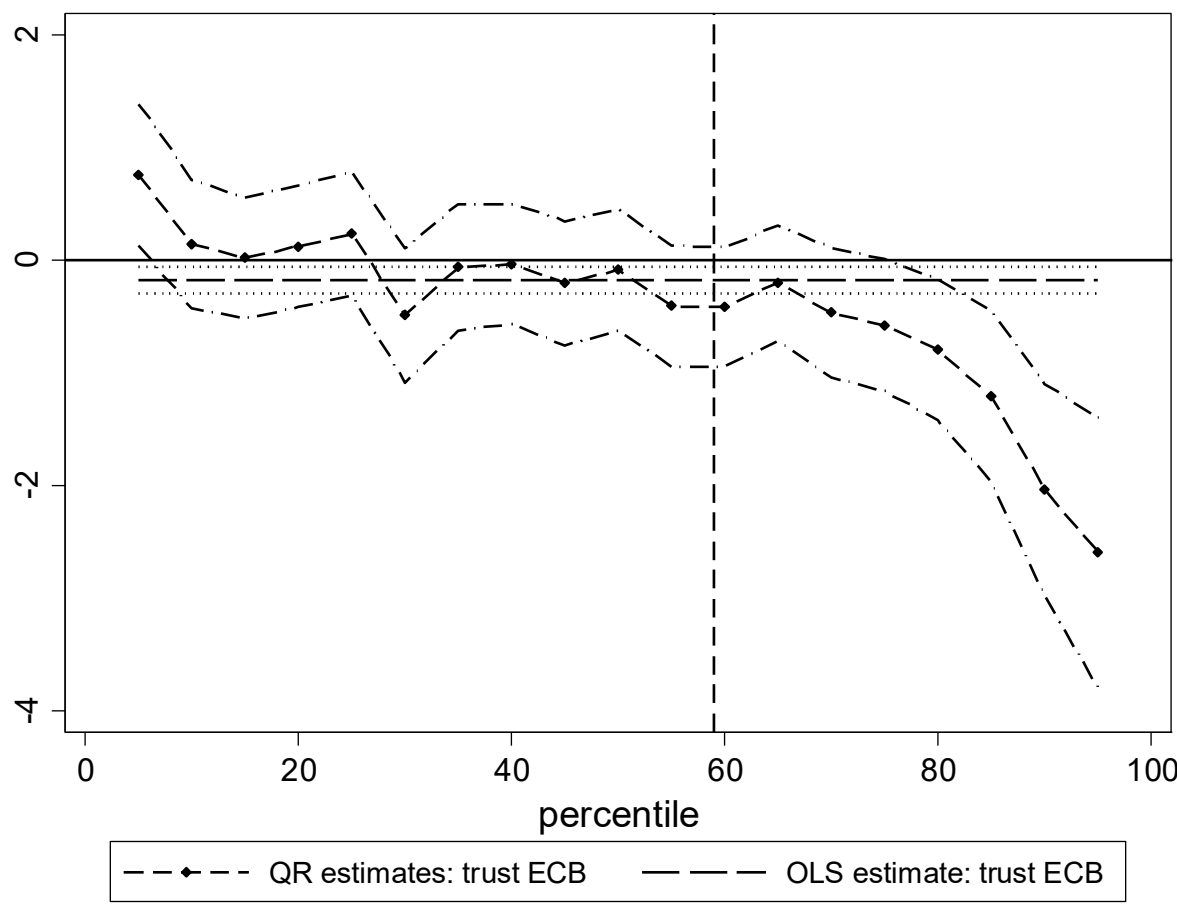


Figure 10. Average expected GDP growth rate by levels of trust in the ECB

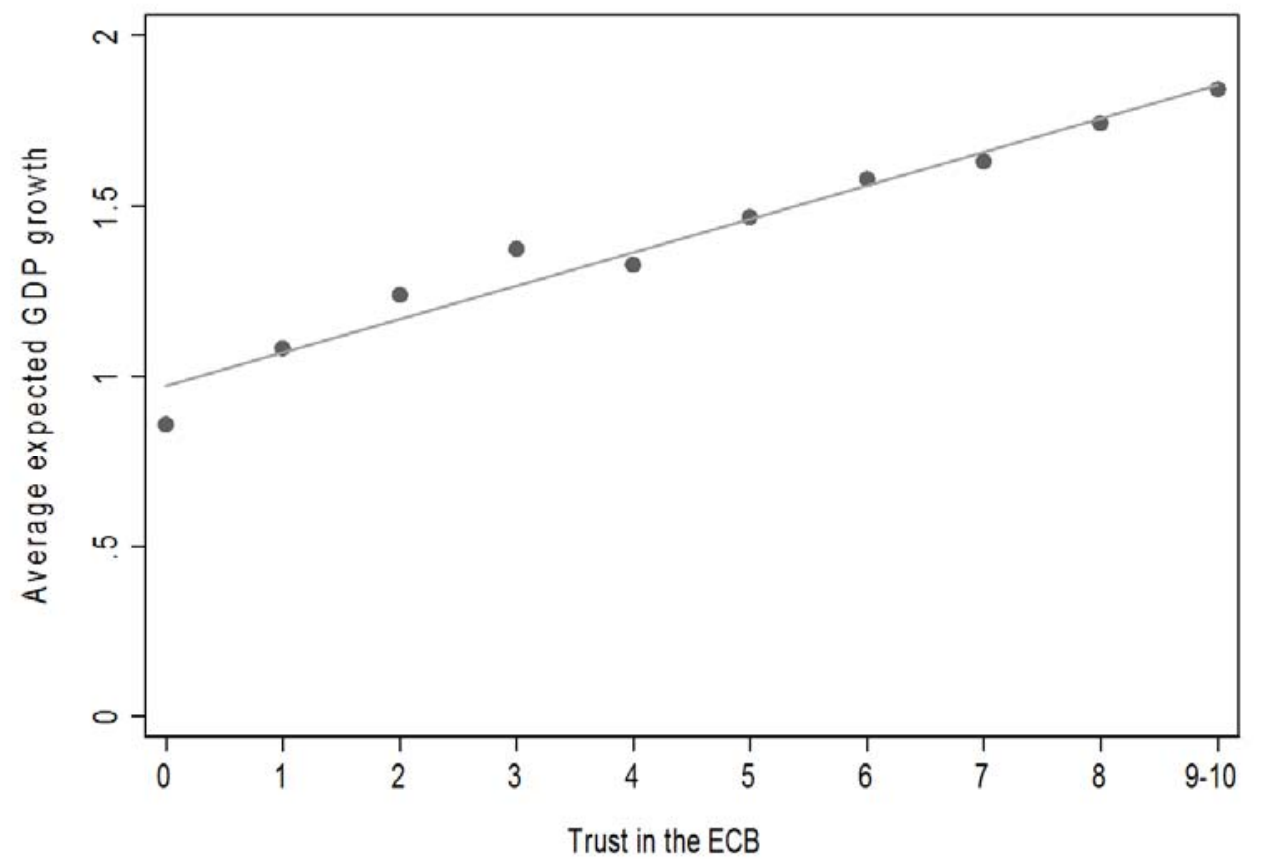

Figure 11. Variance of expected GDP growth rate by levels of trust in the ECB

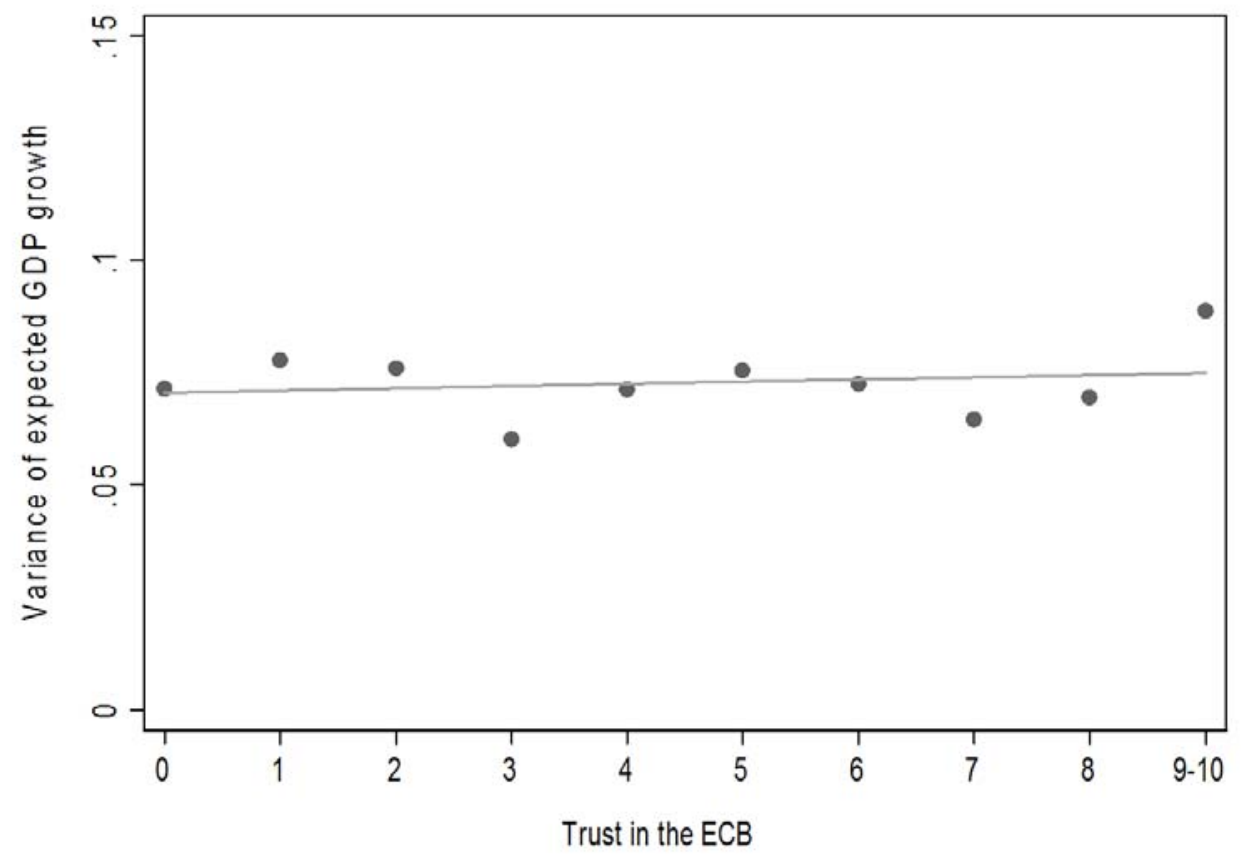

